\title{
FORMAÇÃO EM EDUCAÇÃO FÍSICA: UMA REFLEXÃO COMPARATIVA ENTRE DUAS REALIDADES
}

\author{
TRAINING IN PHYSICAL EDUCATION: A COMPARATIVE REFLECTION \\ BETWEEN TWO REALITIES
}

\begin{abstract}
FORMACIÓN EN EDUCACIÓN FÍSICA: UNA REFLEXIÓN COMPARATIVA ENTRE DOS REALIDADES
\end{abstract}

Viviana Graziela de Almeida Vasconcelos Barboni*, Elson Moura Dias Junior*

Palavras chave:

Formação.

Educação Física

Universidades.

Currículo.
Resumo: Este trabalho analisa as diferenças entre os cursos de Educação Física da Universidade Estadual de Feira de Santana, no Brasil, e a Faculdade de Ciência do Desporto e Educação Física da Universidade de Coimbra, em Portugal, confrontando documentos de ambas as universidades. Foram analisadas as categorias: tempo de formação, elenco de disciplinas, concepção de licenciatura e bacharelado e perfil profissional; salientando principalmente os contextos histórico, social e político díspares em que ambas as universidades estão inseridas, e o reflexo disso nos currículos, metodologias e didáticas díspares. Identificou-se forte impacto do contexto histórico e social na construção dos currículos universitários, e no traçado do perfil profissional que cada universidade busca formar.
Keywords:

Training.

Physical Education.

Universities.

Curriculum.
Abstract: This paper analyzes the differences between undergraduate courses in Physical Education from the State University of Feira de Santana, Brazil, and the College of Sport Science and Physical Education of the University of Coimbra, Portugal, by comparing documents from both universities. The categories examined included: training time, list of disciplines, teacher's training and bachelor's degrees views, and professional profile, emphasizing the distinct historical, social and political contexts of both universities and their impact on curricula, methodology, and didactics. It found strong impact by historical and social context on construction of curricula and professional profile that each university seeks.

Palabras clave: Formación. Educación Física. Universidades. Currículo.
Resumen: Este artículo analiza las diferencias entre el grado de licenciatura en Educación Física de la Universidad Estadual de Feira de Santana, en Brasil, y la Facultad de Ciencias del Deporte y Educación Física de la Universidad de Coimbra, en Portugal, comparando documentos de ambas universidades. Se analizaron las categorías: tiempo de formación, oferta de disciplinas, concepción de licenciatura y bachillerato, y perfil profesional; destacando principalmente los contextos histórico, social y político dispares en que las dos universidades se insieren y el reflejo de esto en los currículos de estudio, metodologías y didácticas, también desiguales. Se identificó fuerte impacto del contexto histórico y social sobre la construcción de currículos universitarios y el diseño del perfil profesional que cada universidad se propone formar.
*Universidade Estadual de Feira de Santana. Feira de Santana, BA, Brasil. E-mail: vivianabarboni@yahoo.com.br

Recebido em: 21-04-2016 Aprovado em: 08-12-2016

(c) (1) (8) Licence 


\section{INTRODUÇÃOO}

Brasil e Portugal mantêm estreita relação econômica, comercial e intercultural, proveniente de um processo histórico que se originou no período da colonização. Essa relação histórica garantiu uma matriz linguística comum e consequentemente a relação de proximidade dos dois países ao longo dos anos, sendo reforçada ainda mais no mundo globalizado atual através de fluxo intenso de informações e pessoas.

Esse contexto de fluxo de pessoas envolve o fenômeno de mobilidade estudantil, crescente até 0 ano de 2016 no Brasil', devido ao aumento de número de programas governamentais e de iniciativa privada de apoio e incentivo ao intercâmbio no exterior, sobretudo em Portugal (MOROSINI, 2011). Esses incentivos possibilitavam a um grande número de estudantes realizar um curso de nível superior, ou pelo menos parte dele, em universidades estrangeiras, tendo a chance de entrar em contato com outra cultura, vivenciar outro idioma e poder acessar o conhecimento produzido por profissionais de outros países. São esses desafios provocados pelo choque cultural que inquietam e possibilitam os questionamentos, desenvolvimento e o crescimento desses estudantes.

No Brasil, a área de Educação Física passa por uma crise epistemológica (TAFFAREL; TEIXEIRA; D'AGOS, 2005), em que ainda se discute muito sobre currículo e formação, e ainda se tem muitos questionamentos sobre campos de atuação, objeto de estudo e papel do professor de Educação Física. Nesse sentido, a experiência em outra realidade pode ser peculiarmente enriquecedora para a compreensão de algumas dessas questões, bem como pode, em contrapartida, suscitar novos questionamentos, o que é fundamental para a construção da maturidade científica de um estudante em formação.

Dentro desse panorama, este trabalho busca elucidar as principais diferenças encontradas, durante 0 intercâmbio acadêmico, entre os cursos de Educação Física da Faculdade de Ciências do Desporto e Educação Física (FCDEF) da Universidade de Coimbra, em Portugal, e da Universidade Estadual de Feira de Santana (UEFS), no Brasil, realizado no primeiro semestre do ano de 2015.

Vivenciar um curso de Educação Física em uma universidade pública brasileira que evidencia e busca fazer jus ao tripé Ensino, Pesquisa e Extensão conduziu a um choque cultural no confronto com a realidade portuguesa, em que isto não é percebido tão claramente, provocando assim diversos questionamentos. De fato existem diferenças entre as duas universidades? Que elementos sócio-históricos de cada país compõem os cenários dos dois cursos e de que forma influenciam a construção dos currículos de Educação Física?

\section{CONTEXTO PORTUGUÊS PARA ENTENDER O CURRÍCULO DA FCDEF}

A Universidade de Coimbra (UC) é uma das universidades mais antigas da Europa, fundada em 1290, antes mesmo da colonização do Brasil, e carrega um legado histórico multissecular de intenso tradicionalismo.

Localizada ainda em um país pertencente ao bloco econômico da União Europeia e da Zona do Euro, apresenta marcantes características de internacionalização e globalização, e

1 Em 2016 o governo Temer (PMDB), após impeachment do governo Dilma (PT), suspendeu o programa Ciência Sem Fronteiras, o maior programa nacional de intercâmbio estudantil para troca de experiências, estímulo à inovação e fortalecimento da ciência. 
traços fortes da economia neoliberal, inclusive no estatuto da universidade. Assim, mesmo sem possuir autonomia financeira, a UC tem como receita, além do repasse estadual, rendimentos derivados de prestação de serviços, venda de publicações e bens, propriedade intelectual, aplicações financeiras, taxas e mensalidades cobradas dos alunos, rendimentos de bens próprios, subsídios, subvenções, comparticipações, doações, heranças e legados, além de ser permitido à universidade criar incentivos para obtenção de receitas próprias (PORTUGAL, 2008).

Essa forma de administrar a universidade pública como uma empresa denota a forte influência neoliberalista na economia e educação do país, estando esta relação administrativa empresarial fortemente presente em universidades de toda a Europa desde o chamado Processo de Bolonha, que reorganizou todo o ensino superior europeu, padronizando e adequando a lógica neoliberalista comercial de pensar educação.

Trata-se do processo político que se iniciou em 1999 em Bolonha, na Itália, de cooperação internacional para reforma e criação de um Espaço Europeu de Ensino Superior, com mobilidade e acesso equitativo livre para estudantes, professores e funcionários ligados à educação superior. Inicialmente firmado entre 29 países europeus, incluindo Portugal, atualmente já conta com adesão de 46 países (DECLARAÇÃO..., 1999).

Antes de Bolonha, as universidades de toda a Europa possuíam autonomia e produção de conhecimento muito ligadas à cultura da nação, estando intimamente dependentes das políticas públicas, legislação e financiamento estatal definido por cada Estado-Nação. No entanto, com o firmamento da União Europeia (UE) enquanto bloco econômico, as pressões para 0 crescimento financeiro e disputa de mercado produziram reflexos nos modelos governamentais de cada país, e posteriormente também na forma de pensar a educação superior, surgindo os modelos mais liberalizantes, distintos dos países nórdicos e mais similares ao modelo angloamericano (LIMA; AZEVEDO; CATANI, 2008).

A Declaração de Bolonha (1999) surgiu então nessa tentativa de unificar cada vez mais as economias da UE, gerar mais capital, tornando o bloco econômico cada vez mais competitivo frente à economia norte-americana. Nesse sentido, o ensino superior começou a ser mercadorizado e o discurso político neoliberalista, que tem na competitividade o foco da produção e geração de lucro, tornou-se a base para a construção da regulamentação do Ensino Superior.

O Processo de Bolonha foi notadamente uma estratégia política e econômica, e não uma estratégia educacional voltada para atender às demandas sociais dos países membros, portanto, teve como principal consequência a redução da autonomia das universidades sobre os direcionamentos da educação, uma vez que as políticas passaram a atender de forma universal demandas específicas de 46 países cultural, social e politicamente diferentes.,

Lima, Azevedo e Catani (2008) fazem a importante ressalva de que as instituições de ensino europeias não foram ouvidas sobre o firmamento do acordo de integração, insuficiente foi o debate público feito e nula a participação popular na tomada de decisão. Como reflexos no Ensino Superior se têm uma formação descontextualizada; a redução do processo democrático de participação popular no que tange à legislação nacional, definida agora em escala europeia; imposição de toda ordem de mecanismos externos à construção do processo educativo, com consequente desempoderamento de estudantes, professores e gestores. 
De que forma isso se refletirá então nos currículos portugueses, mais especificamente no currículo de Educação Física da FCDEF?

Portugal, devido à crise econômica que o país vem enfrentando, desde a sua adesão à Zona do Euro em 1999, tem reduzido o financiamento do Ensino Superior, e diversas medidas de contenção de gastos serão adotadas, tornando ainda mais precárias as condições de ensino. Uma delas apoia-se sobre a Declaração de Bolonha (1999), que, com o objetivo de aumentar a competição com o ensino norte-americano, orienta que se padronize o tempo de duração dos cursos de graduação, igualando aos cursos dos EUA (CRUZ, 2004, p. 6). Com isso, muitos cursos foram obrigados a reduzir seu tempo de formação para graduação.

Dessa forma, em 24 de março de 2006 foi lançado o Decreto-Lei n. 74/2006, que normatiza a educação superior portuguesa adequando-a à Declaração de Bolonha (1999). Segundo esse documento, os cursos de graduação deveriam se limitar ao total de 180 créditos, o que corresponde a três anos de curso, sendo permitidas apenas as graduações em Medicina, Enfermagem, Odontologia, Veterinária, Farmácia, Arquitetura e Engenharia; formações mais longas de quatro, cinco ou seis anos. Os outros cursos que não estivessem adequados a essa referência europeia estariam adotando formações "artificialmente longas" estratégia descrita como "desperdício de recursos" (PORTUGAL, 2006, p. 2242).

Os efeitos dessa normatização vertical do Ensino Superior começaram a se materializar, e já em 2007 a FCDEF produziu o Relatório do Processo de Adequação de Ciclo de Estudos que se referia à adequação do curso às orientações do Processo de Bolonha e ao Decreto-Lei n. $.74 / 2006$ (UNIVERSIDADE DE COIMBRA, 2007). Contrariando a demanda governamental, a FCDEF submeteu um projeto de curso com formação de banda larga, totalizando 240 ECTS, ou seja, oito semestres, através de um currículo que buscava equilibrar áreas de Ciências da Atividade Física, Ciências do Desporto, Ciências da Educação e da Educação Física e ainda uma área interdisciplinar, dedicada ao desenvolvimento de competências profissionais.

A proposta foi recusada, e o curso em vigência foi aprovado com 180 ECTS tal qual a determinação da legislação. Porém, na versão final do relatório, na sessão concernente à justificativa do número de créditos e duração do curso, foi mantido em destaque o seguinte texto:

\footnotetext{
A redacção desta peça permanece tal como na primeira submissão enviada para a Direcção-Geral de Ensino Superior em que era fundamentadamente proposto um plano de estudos de 240 ECTS. Entendeu-se que perde todo o significado ter que justificar uma versão desenhada por imposição superior, pelo que, é mantida a redacção da proposta inicial de adequação (UNIVERSIDADE DE COIMBRA, 2007, p. 29).
}

O trecho deixa bastante claro o "rompimento" que se cria entre Estado e universidades, quando se adota uma política verticalizada, sem participação e escuta popular; que não reflete e nem atende às necessidades da sociedade que representa; voltada para atender prioritariamente a uma lógica de mercado, de competição, com supervalorização de uma cultura estrangeira em detrimento da própria; que fere a autonomia da universidade e que trata a educação como uma oneradora do Estado a ser sacrificada se não der lucro. Foi, portanto, nesse cenário de enxugamento e formação aligeirada que o currículo da Licenciatura em Educação Física da FCDEF se concretizou. 


\section{CONTEXTO BRASILEIRO PARA ENTENDER O CURRÍCULO DA UEFS}

A Constituição Federal brasileira, em seu Capítulo III, define como dever da União garantir uma educação pública, gratuita e de qualidade a toda a população brasileira, e mesmo com a abertura do país para o capital estrangeiro iniciado no governo Collor, e continuado pelos governos FHC (PSDB), Lula/Dilma (PT), e mais recentemente pelo governo Temer (PMDB), a garantia da universidade pública e gratuita ainda prevalece. Estabelece, ainda, que os três pilares da Educação Superior devem ser o ensino, a pesquisa e a extensão, ressaltando a universidade como centro de produção e democratização do conhecimento, e evidenciando sua responsabilidade social com a comunidade em que se insere, uma vez que essas instituições são mantidas com recurso público.

São nesses princípios constitucionais que as instituições de Ensino Superior públicas irão se basear para criação de seus estatutos, e da mesma forma, os cursos construirão seus Projetos Políticos Pedagógicos (UNIVERSIDADE ESTADUAL DE FEIRA DE SANTANA, 2011).

A criação de cursos para atender demandas de mercado, declaradamente voltados para aumentar a competitividade dos seus egressos no mercado de trabalho e assim atrair cada vez mais alunos, gerando mais lucro, é vista mais comumente em faculdades particulares, cuja finalidade é o enriquecimento do indivíduo ou grupo mantenedor. As universidades públicas brasileiras não foram projetadas para funcionar como empresas na medida em que não obtém lucro com a matrícula de estudantes, sendo mantidas através de financiamento público.

Nesse grande panorama das universidades brasileiras, encontra-se a UEFS, uma universidade jovem, localizada em uma cidade do interior do nordeste brasileiro, que nasceu em 1968, com a criação da Faculdade de Educação, para suprir a necessidade de democratização do acesso ao Ensino Superior no interior do Estado da Bahia (UNIVERSIDADE ESTADUAL DE FEIRA DE SANTANA, 2013).

Situada em uma região de intensas contradições socioeconômicas, essa instituição apresenta no seu estatuto como principal missão social o compromisso com o desenvolvimento sustentável da Região do Semiárido baiano, evidenciando a identidade da universidade com a região à qual pertence e forte regionalização.

Obedecendo este propósito, é fundado o curso de Licenciatura em Educação Física da UEFS, no ano de 1997, objetivando suprir uma carência do município, sinalizada pela DIREC 02, de professores de Educação Física com nível superior tanto no ensino básico como nos ambientes não escolares, de Feira de Santana e região.

O curso surgiu com uma grade curricular que buscava englobar conhecimentos das áreas das Ciências Biológicas e Naturais, das Ciências Humanas, dos conhecimentos didáticopedagógicos e dos conhecimentos específicos, principalmente as práticas esportivas. No entanto, com a superação do modelo esportivizante adotado para o currículo, fez-se necessária uma reformulação curricular, em 2004, justificada pela necessidade de incorporar a pesquisa, a formação didático-pedagógica e os conhecimentos advindos da experiência com a prática profissional na nova proposta. Assim, o novo currículo foi construído, agregando as novas ideias e assumindo como referência a concepção filosófica que compreende a Educação Física como uma área de intervenção historicamente construída, tendo em seu eixo epistemológico de estudo os elementos da Cultura Corporal de Movimento (UNIVERSIDADE ESTADUAL DE FEIRA DE SANTANA, 2011). 
No entanto, a materialização desse currículo ainda é um desafio. E ainda que encontre defesa exaustiva de uma pedagogia progressista e crítica no Projeto Político Pedagógico (PPP), mesmo possuindo um grupo ativo na militância e engajado politicamente, mesmo com toda a pretensão de se formar profissionais críticos de sua práxis através de um currículo que busque envolver o ensino, pesquisa e extensão, o curso encontra entraves sérios, não possui unanimidade epistemológica e a compreensão de EF presente no PPP não é acordo entre 0 quadro docente.

Assim temos o currículo da UEFS regionalizado, preocupado em atender as demandas nacionais, regionais e até locais, envolvido com os problemas da sociedade em que está inserido, preocupado em contextualizar o profissional que forma neste contexto. Em contraponto, há em Portugal o currículo internacionalizado europeu, visando resolver os problemas econômicos de todo um continente.

\section{DIFERENÇAS ENTRE OS CURSOS}

As diferenças entre os dois cursos foram levantadas a partir da Análise de Conteúdo proposta por Bardin (2009), de documentos das duas universidades, sendo eles: PPP do curso da UEFS e o Processo de Adequação de Ciclo de Estudos do curso de Educação Física da FCDEF, componentes curriculares e ementas dos dois cursos e Legislação profissional e educacional dos dois países pertinentes, além de outros documentos complementares. As categorias de análise levantadas foram três: concepção de licenciatura e bacharelado, tempo de formação e elenco de disciplinas e perfil profissional.

\subsection{Licenciatura X Bacharelado}

Até 2008 a FCDEF apresentou um currículo dicotomizado em Licenciatura em Educação Física e Licenciatura em Ciências do Desporto, que pode admitir se tratar da mesma dicotomia brasileira em licenciatura e bacharelado. No entanto, no mesmo ano se tornou vigente o novo currículo unificado de Licenciatura em Ciências do Desporto e Educação Física (UNIVERSIDADE DE COIMBRA, 2007).

Esta medida será baseada no documento aprovado na reunião do plenário do Conselho de Reitores da Universidades Portuguesas, em 2005 (CONSELHO DE REITORES DAS UNIVERSIDADES PORTUGUESAS, 2005), que critica a proliferação de cursos e designações, orientando a unificação com adoção de uma matriz única para os cursos de graduação dicotomizados (UNIVERSIDADE DE COIMBRA, 2007, p. 3). Esta será mais uma das medidas de redução de gastos do governo português com o Ensino Superior.

Sem a intencionalidade de redução de gastos, mas por razões igualmente subservientes a uma lógica de mercado, o Conselho Pedagógico da FCDEF posicionou-se em acordo com esta medida:

A adequação do seu projecto científico-pedagógico, traduzido na fusão das duas licenciaturas, num só plano designado de Licenciatura em Ciências do Desporto deve-se também aos dados do observatório de inserção profissional, que desligam o mercado profissional do perfil de saída. As oportunidades de emprego nos anos imediatos à obtenção do grau de licenciado são de exercício pluri-profissional, pelo que uma formação estreita revelar-se-ia limitadora (UNIVERSIDADE DE COIMBRA, 2007, p. 32). 
Percebe-se, assim, mais uma vez, a universidade se pondo a serviço dos interesses do capital e de mercado, orientando a construção curricular do curso de Educação Física pelas necessidades de mercado, e não visando o desenvolvimento do indivíduo e da coletividade em que ele se insere.

No Brasil, a dicotomia entre licenciatura e bacharelado na área da Educação Física é uma polêmica gerada especialmente por divergências na interpretação da legislação.

As Diretrizes Curriculares Nacionais para o curso de graduação em Educação Física foram estabelecidas na Resolução CNE/CES nํ07/2004, que utiliza os termos licenciatura plena e graduação plena para caracterizar as competências a serem desenvolvidas de maneira geral pelos cursos de graduação em Educação Física. Ou seja, não distingue campos de atuação de licenciatura e bacharelado, apesar de considerar as especificidades da licenciatura, que deve atender também às Diretrizes Curriculares Nacionais para Formação de Professores da Educação Básica dispostas na resolução CNE/CP nํ2, de 1ํ de julho de 2015 (BRASIL, 2015).

O termo graduação plena é amplo e engloba também a licenciatura segundo a Lei nº 9.394/96, que define graduação como todo curso de nível superior "aberto a candidatos que tenham concluído o ensino médio ou equivalente e tenham sido classificados em processo seletivo" (BRASIL, 1996, art. 44. Inciso II). Ou seja, a resolução CNE/CES no 07/2004 não traça diretrizes diferenciadas para graduação e para a licenciatura, mas sim diretrizes gerais para a graduação, ressaltando a especificidade da licenciatura em adequar-se também a outra resolução.

O Conselho Federal de Educação Física (CONFEF), no entanto, fará má interpretação do texto da resolução, estabelecendo na Resolução CONFEF no 269/2014 diferenças entre os cursos de Educação Física no Brasil enquanto "Licenciatura e Graduação (Bacharelado)", ou seja, aplicando o termo graduação plena, utilizado na normatização da CNE/CES no 7/2004, como sinônimo de bacharelado. Essa diferenciação é justificada pelo Conselho utilizando a própria resolução CNE/CES $n^{\circ} 7 / 2004$, demonstrando o viés interpretativo adotado pelo CONFEF sobre os termos utilizados na resolução.

Como consequência, a atuação profissional da licenciatura passa a se restringir, segundo o CONFEF, à Educação Básica, enquanto todas as outras possibilidades de atuação dispostas pela Resolução CNE/CES n- 7/2004 passam a ser exclusivas ao bacharel. Cria-se então uma restrição profissional baseada no campo de atuação, que irá gerar conflitos judiciais entre profissionais e instituições da área e o CONFEF e Conselhos Regionais de Educação Física (CREF).

$\mathrm{Na}$ instância acadêmica, esses conflitos repercutem gerando amplo debate entre os profissionais da área sobre a real diferença de atuação entre as duas formações, e se existe diferença de fato, uma vez que ambas se qualificam como atividade docente, dando margem à defesa da formação unificada com a extinção do bacharelado. O CONFEF e CREF, por outro lado, defendem a fragmentação da formação e a restrição da atuação com a justificativa de ampliar o mercado de trabalho e o número de federados, gerando mais lucro e fortalecendo economicamente os conselhos.

Em 2015 ainda, uma Minuta de Projeto de Resolução foi publicada pelo CNE do Ministério da Educação (MEC), propondo instituir novas Diretrizes Curriculares Nacionais para os cursos de graduação em Educação Física, causando muita polêmica por propor a 
extinção dos cursos de bacharelado em Educação Física (BRASIL, 2015), subentendendo que a formação acadêmica na área ocorreria, exclusivamente, pela licenciatura. 0 projeto foi debatido no dia 11 de dezembro de 2015 em uma plenária de audiência pública no próprio CNE/ $M E C$, porém a referida proposta foi criticada pelo próprio CONFEF e refutada. Esta minuta se caracteriza como um importante ponto de partida para futuras discussões públicas sobre 0 tema da dicotomia na formação.

Verifica-se, então, que, assim como em Portugal, no Brasil também existe uma tendência a sobrepor os interesses econômicos à formação profissional de qualidade, compreensível, uma vez que são dois países com economia de base capitalista, porém os interesses que levam ambas as universidades a defenderem um currículo unificado são opostos. Enquanto que na UC o interesse na unificação está alinhado com a lógica de mercado do Estado, na UEFS o interesse é contra-hegemônico.

No Brasil algumas universidades impõem resistência à regulamentação do CONFEF, e em 2011, o curso de Educação Física da Universidade Federal de Santa Maria, no Rio Grande do Sul, tentou aprovar o primeiro currículo unificado no país, contemplando legalmente a formação tanto em licenciatura quanto do bacharelado, e buscando superar todos os obstáculos impostos pelo CONFEF/CREF. Porém sua implantação não foi bem-sucedida.

O curso da UEFS, em acordo com essa perspectiva de unificação, até o ano de 2015 teve uma liminar judicial que impedia o CONFEF e CREF13/BA-SE de limitarem a atuação dos egressos licenciados em áreas de atuação ditas como de jurisprudência dos bacharéis (BAHIA, 2012). Em seu PPP trará explícita a defesa da unificação através de "[...] uma formação sólida, capaz de lhes instrumentalizar a intervirem nos distintos campos em que a Educação Física se insere, reconhecendo que o que unifica a atuação nos diversos espaços é o trabalho docente" (UNIVERSIDADE ESTADUAL DE FEIRA DE SANTANA, 2011, p. 23, grifo nosso).

Isso evidencia que o curso da UEFS apresenta criticidade e enfrentamento das determinações normativas até mesmo do próprio conselho, colocando em primeiro lugar os interesses da sociedade enquanto coletivo. Evidencia ainda o poder de argumentação, participação na militância e movimentos de luta da área por melhorias, e não o conformismo, revelando o quanto as universidades brasileiras ainda possuem uma autonomia maior do que as portuguesas no que se refere a enfrentar as decisões do Estado, fazendo frente de oposição e não apenas acatando as ordens superiores. O longo histórico de greves bemsucedidas que ocorreram na UEFS nos últimos dez anos deixa isso muito evidente quando comparado à UC.

\subsection{Tempo de Formação e Elenco de Disciplinas}

O curso da Uefs apresenta um Currículo Pleno de 3.430 horas, distribuídas em oito semestres, sendo: 2.190 horas de disciplinas obrigatórias; 240 horas de disciplinas optativas; 200 horas de atividades complementares; 400 horas de prática como Componente Curricular; e 400 horas de Estágio Curricular Obrigatório.

As disciplinas obrigatórias se organizam segundo o quadro abaixo (Quadro 1), contemplando diferentes áreas do conhecimento: 
Quadro 1 - Disciplinas do Currículo de Educação Física da UEFS organizado por áreas do conhecimento

\begin{tabular}{|l|l|}
\hline $\begin{array}{l}\text { Área do } \\
\text { conhecimento }\end{array}$ & \multicolumn{1}{c|}{ Disciplinas } \\
\hline $\begin{array}{l}\text { Biológicas e } \\
\text { Biomédicas (450h) }\end{array}$ & $\begin{array}{l}\text { Biologia Humana Aplicada à Educação Física (75h); Anatomia Aplicada à Educação } \\
\text { Física (75h); Bioquímica Aplicada à Educação Física (60h); Cinesiologia (60h); } \\
\text { Fisiologia Humana (60h); Fisiologia do Exercício (60h); Primeiros Socorros (60h) }\end{array}$ \\
\hline $\begin{array}{l}\text { Análise Sócio-Antropológica da Educação Física, Esporte e Lazer (60h); Análise } \\
\text { Histórica da Educação Física, Esporte e Lazer (60h); Análise Filosófica da Educação } \\
\text { Educação Física } \\
\text { (1110h) }\end{array}$ & $\begin{array}{l}\text { Física, Esporte e Lazer (60h); Metodologia do Ensino da Ginástica (60h); Educação } \\
\text { da Dança (75h); Estudos das Manifestações Culturais (75h); Nutrição Aplicada à } \\
\text { Educação Física (60h); Medidas e Avaliação em Educação Física (60h); Atividade } \\
\text { Física e Saúde Coletiva (75h); Metodologia do Ensino do Esporte I (90h); Metodologia } \\
\text { do Ensino das Atividades Aquáticas (75h); Metodologia do Ensino do Esporte II (90h); } \\
\text { Treinamento Desportivo (60h); Trabalho e Lazer (60h). }\end{array}$ \\
\hline $\begin{array}{l}\text { Área Pedagógica } \\
\text { (405h) }\end{array}$ & $\begin{array}{l}\text { Psicologia do Desenvolvimento e da Aprendizagem (60h); Didática (75h); Metodologia } \\
\text { do Ensino da Educação Física (75h); Política e Gestão Educacional (75h); } \\
\text { Desenvolvimento e Aprendizagem Motora (60h); Políticas Públicas, Planejamento e } \\
\text { Gestão em Educação Física (60h) }\end{array}$ \\
\hline $\begin{array}{l}\text { Formação Científica } \\
\text { (225h) }\end{array}$ & $\begin{array}{l}\text { Introdução ao Trabalho Científico (75h); Seminário de Projeto de Pesquisa (75h); } \\
\text { Monografia (75h). }\end{array}$ \\
\hline
\end{tabular}

Fonte: UNIVERSIDADE ESTADUAL DE FEIRA DE SANTANA, 2016

Nota-se que além da formação específica, biológica e pedagógica, o curso ainda contempla 225 horas para a formação científica, exigindo a defesa de uma monografia para obtenção do grau. Associada a isso há ainda a exigência de 200 horas em formação complementar, que traduz a participação em eventos, cursos e grupos de estudos, apresentação de trabalhos, organização de eventos, participação em movimento/representação estudantil, entre outras coisas que são entendidas como parte fundamental na formação do estudante além da sala de aula.

O curso conta ainda com diferentes grupos de pesquisa e extensão que acolhem estudantes todos os semestres envolvendo-os nas suas atividades e colocando-os em contato com a reflexão, pesquisa e prática em Educação Física durante a graduação.

Percebe-se que se trata de um currículo, tal qual descrito no PPP do curso, orientado para uma formação que não busca atender exclusivamente o mercado de trabalho, mas sim a formação de indivíduos críticos, agentes de transformação (UNIVERSIDADE ESTADUAL DE FEIRA DE SANTANA, 2011).

$\mathrm{Na}$ face europeia, resgatando o currículo antigo, no período da dicotomia, havia uma licenciatura com duração de quatro anos, ou seja, com 240 ECTS, sendo 90 ECTS pertencentes a áreas obrigatórias em Ciências da Atividade Física; 60 ECTS obrigatórios em Ciências da Educação, e ainda 30 ECTS em unidades curriculares optativas das áreas de Ciências da Atividade Física e Ciências do Desporto. Além disso, havia mais 60 ECTS obrigatórios, sendo 40 ECTS em Estágio e 20 ECTS em Seminário (não é explicitada em nenhum dos documentos analisados a natureza desse componente). Observa-se, então, uma estrutura de currículo com elementos similares à proposta da UEFS.

O currículo atual, no entanto, é bem diferente, muito mais enxuto e ainda menos diverso do que 0 anterior. 
Já de início, o período de formação é de três anos, correspondentes a 180 ECTS, sendo: 57.0 ECTS para a área de Ciências da Atividade Física, 64.5 ECTS para a área de Ciências do Desporto e 58.5 ECTS para Ciências da Educação Física, estando dispostas detalhadamente no quadro abaixo (Quadro 2) as disciplinas por área do conhecimento segundo o currículo da FCDEF. O sistema de ECTS contabiliza horas de contato com o professor, mais horas de estudo em casa, avaliação, trabalhos, projetos e estágios, transformando isso em uma porcentagem. No entanto, para efeito de comparação entre os dois currículos, foi considerada apenas a carga horária absoluta de horas aula.

Quadro 2 - Disciplinas do Currículo de Educação Física da FCDEF organizado por áreas do conhecimento

\begin{tabular}{|l|l|}
\hline $\begin{array}{l}\text { Área do } \\
\text { conhecimento }\end{array}$ & \multicolumn{1}{c|}{ Disciplinas } \\
\hline $\begin{array}{l}\text { Ciências da } \\
\text { Atividade Física } \\
\text { (510h) }\end{array}$ & $\begin{array}{l}\text { Cinesiologia I (45h); Cinesiologia II (45h); Cineantropologia (45h); Fisiologia Geral } \\
\text { I (45); Fisiologia Geral II (45h); Iniciação à Estatística (45h); Desenvolvimento e } \\
\text { Adaptação Motora (45h); Biomecânica (45h); Controlo Motor e Aprendizagem (45h); } \\
\text { Bioquímica do Exercício (60h); Fisiologia do Exercício (45h); Prescrição do Exercício } \\
\text { (60h). }\end{array}$ \\
\hline $\begin{array}{l}\text { Auxologia e Cineantropometria (45h); Desporto Infanto-Juvenil (60h); Planeamento } \\
\text { e Periodização do Treino (60h); Desporto de Opção I (60h); Desporto de Opção II } \\
\text { (60h); Psicologia do Desporto (40h); Desporto e Exercício em Populações Especiais } \\
\text { (40h); Gerontologia Educativa e Desportiva (40h); Organização das Actividades de } \\
\text { Lazer (40h); Métodos de Condicionamento Físico (60h); Nutrição e Desporto (40h); } \\
\text { Metodologia do Treino de Jovens Atletas (60h); Organização e Gestão do Desporto } \\
\text { (40h). }\end{array}$ \\
$\begin{array}{l}\text { Estudos Práticos I (180h); Estudos Práticos II (180h); Estudos Práticos III (180h); } \\
\text { História da Educação (45h); Sociologia da Educação (45h); Pedagogia do Desporto } \\
\text { Educação Física } \\
\text { (1500h); Prática de Ensino (60h); Análise de Ensino (40h); Análise das Organizações } \\
\text { Educativas (40h); Ensino Integrado em Educação Física (45h); Desenvolvimento } \\
\text { Curricular (40h). }\end{array}$ \\
\hline
\end{tabular}

Fonte: UNIVERSIDADE DE COIMBRA, 2016.

O novo currículo não apesenta exigência de estágio, ao invés disso existem as disciplinas chamadas "Desportos de Opção", que são modalidades esportivas que os estudantes escolhem para estagiar e se aprofundar.

A seu critério o estudante pode obter formação complementar em disciplinas optativas de outros cursos da UC, mas não há exigências para ambas as categorias. Observa-se um currículo bem enxuto, em que o único critério para obtenção do grau de licenciado é aprovação nas disciplinas obrigatórias, enxugamento que visa atender a redução de gastos com ensino superior pelo governo português, bem como as demandas internacionais do Processo de Bolonha.

\subsection{Perfil Profissional}

A UEFS, enquanto uma universidade do interior do nordeste brasileiro, centro do saber e produção do conhecimento, que visa mitigar os problemas da região, principalmente causados pela desigualdade social, visa formar profissionais com compromisso político; que compreendam a realidade econômica, política e sociocultural brasileira; capazes de adaptar 0 seu trabalho às novas demandas socioculturais dos alunos (UNIVERSIDADE ESTADUAL DE FEIRA DE SANTANA, 2011). 
Enquanto defensor de uma formação unificada, o curso ainda propõe que o egresso desenvolva competências em ambas as áreas, tanto as listadas na Resolução CNE/CP n01/2002 quanto na Resolução CNE/CES nº 07/2004, apesar de não apresentar um currículo de matriz unificada.

A FCDEF, por outro lado, já busca formar um outro perfil, observado desde o processo seletivo, que tem como etapa eliminatória um teste de aptidão física com provas de natação e atletismo (UNIVERSIDADE DE COIMBRA, 2015), normatizada segundo uma deliberação nacional (PORTUGAL, 2015, p. 4926). No Brasil esse tipo de seleção já foi há anos extinto, seus critérios de exclusão são considerados ultrapassados e essa metodologia é muito mal vista na área.

Sendo uma universidade que evita o conflito com o Estado na defesa da formação que acredita, visa formar profissionais apenas para atender às demandas do mercado de trabalho e às expectativas de aumento da competitividade internacional proposto pelo Processo de Bolonha, a FCDEF acaba por ser conivente com as políticas de redução de gastos do governo português com o Ensino Superior, e forma profissionais de Educação Física acríticos, capacitados apenas para reproduzir os conhecimentos adquiridos sem refletir ou questionar.

$\mathrm{Na}$ lista de competências que a FCDEF pretende desenvolver em seus egressos, encontrada no projeto de implantação do curso, está contemplado o desenvolvimento de diversas competências técnicas, tais como elaboração de políticas desportivas, orientação de programas de desporto autárquico, treino desportivo e orientação de programas de condição física e educação para a saúde, no entanto não há menção à transformação da realidade (UNIVERSIDADE DE COIMBRA, 2007).

Percebe-se, assim, que todas as diferenças de contexto e de currículo culminam numa formação profissional com direcionamentos distintos: o brasileiro mais voltado à superação da realidade social, enquanto o português volta-se à sua manutenção.

\section{CONSIDERAÇÕES FINAIS}

Sem a intenção de julgar qual o melhor curso, qual o melhor currículo, ou que profissional será mais bem preparado, esse trabalho buscou entender a realidade socioeconômica dos dois países, analisando as implicações que ela tem para a formação em Educação Física nos dois países. Portanto, entende-se que Brasil e Portugal estão inseridos em contextos diferentes, apresentam uma relação histórica de colonização em que ambos protagonizaram faces antagônicas, e em decorrência disso possuem hoje contextos político, socioeconômico e cultural que demandam formações diferentes para seus profissionais de Educação Física.

Compreende-se que ambas as universidades se deparam com determinações do Estado, algumas vezes contraditórias aos seus próprios interesses, porém na face portuguesa o contexto econômico e político pesou muito mais sobre a construção do currículo, que não encontrou na UC resistência às determinações do Estado, passando este a agir como um mediador entre mercado e formação profissional. Por outro lado, no Brasil, mesmo com o sucateamento do Ensino Superior, que traz historicamente essa marca de intelectualidade crítica, reivindicações, greves e movimento sindical, o Estado ainda encontra resistência às tentativas de redução de custos e cortes de verbas para a educação. 
A posição política da universidade, portanto, influenciada pelo contexto socioeconômico do país, gera as diferenças entre os dois cursos, e como consequência a formação de profissionais comprometidos com a manutenção ou transformação da realidade. Na UEFS, isso se traduz no curso de Educação Física através de uma formação voltada para atender às necessidades da sociedade e de sua transformação, o que implica tempo de curso maior, a defesa da formação unificada, presença de disciplinas na área política e filosófica, inserção do aluno de graduação em extensão e pesquisa, além da exigência de atividades complementares. Por outro lado, na FCDEF, a preocupação prioritária será em formar profissionais competitivos, através de uma formação rápida, enxuta e mais técnica.

Essas constatações auxiliam a compreender a importância da autonomia universitária, da luta por uma educação crítica e não subserviente a interesses mercadológicos. Também ajudam a compreender que cada país desenvolve um modelo que melhor atende às suas necessidades, portanto, é importante que se fortaleça o modelo de universidade brasileira, que busca a produção e a democratização do conhecimento, que visa transformar a sociedade, contrário ao modelo explorador e empresarial norte-americano, tantas vezes citado como exemplo a ser seguido pelo Ensino Superior brasileiro.

\section{REFERÊNCIAS}

BAHIA. Seção Judiciária da Bahia. Justiça Federal de $1^{1}$ Instância. Sentença Tipo A. Processo ${ }^{\circ}$ : 44645-56.2011.4.01.3300/ 10ª Vara. Ministério Público Federal e Conselho Federal de Educação Física (CONFEF) e outro. Relator: Evandro Reimão dos Reis. Salvador, 24 de dez. 2012. Disponível em: <http://www.bio.ufpr.br/portal/def/wp-content/uploads/sites/16/2014/06/acao civil_publica BA.pdf>. Acesso em: 17 fev. 2017.

BARDIN, Laurence. Análise de conteúdo. Lisboa: Edições 70, 2009.

BRASIL. Conselho Federal de Educação Física. Resolução CONFEF no 269 de 7 de abril de 2014. Dispõe sobre os documentos necessários para inscrição profissional no âmbito do Sistema CONFEF/CREFs. Disponível em: <http://www.confef.org.br/extra/resolucoes/conteudo.asp?cd resol=342\&textoBusca $=>$. Acesso em: 17 fev. 2017.

BRASIL. Conselho Nacional de Educação. Minuta de Projeto de Resolução para audiência pública de 11 de dezembro de 2015. Institui Diretrizes Curriculares Nacionais para o curso de graduação em Educação Física, Licenciatura. Disponível em: <http://www.cbce.org.br/upload/biblioteca/Proposta\%20 de\%20Resolu\%C3\%A7\%C3\%A3o DCN\%20Educa\%C3\%A7\%C3\%A30\%20F\%C3\%ADsica\%20 licenciatura.pdf>. Acesso em: 21 nov. 2016.

BRASIL. Conselho Nacional de Educação. Resolução CNE/CP no 1 de 18 de fevereiro 2002. Define as Diretrizes Curriculares Nacionais para a formação inicial em nível superior (cursos de licenciatura, cursos de formação pedagógica para graduados e cursos de segunda licenciatura) e para a formação continuada. Disponível em: <http://portal.mec.gov.br/cne/arquivos/pdf/rcp01 02.pdf>. Acesso em: 17 fev. 2017.

BRASIL. Lei no 9.394, de 20 de dezembro de 1996. Estabelece as diretrizes e bases da educação nacional. Disponível em: <http://www.planalto.gov.br/ccivil 03/leis/L9394.htm>. Acesso em: 17 fev. 2017. 
BRASIL. Resolução n 7, de 31 de março de 2004. Institui Diretrizes Curriculares Nacionais para os cursos de graduação em Educação Física, em nível superior de graduação plena. Disponível em: $<$ http://portal.mec.gov.br/cne/arquivos/pdf/ces0704edfisica.pdf>. Acesso em: 17 fev. 2017.

CONSELHO DE REITORES DAS UNIVERSIDADES PORTUGUESAS. Ensino Superior: Ordenamento da Oferta Educativa. Documento aprovado na reunião do Plenário do Conselho de Reitores das Universidades Portuguesas, de 14 dez. 2005, p. 21. Disponível em: <www.snesup.pt/ htmls/ dlds/ordenamento oferta educativa2.pdf>. Acesso em: 28 out. 2016.

CRUZ, Manuel Braga. Implementação do Processo de Bolonha a nível nacional Grupos por Área de Conhecimento: Ciências Sociais. Lisboa: Universidade Católica Portuguesa, 2004. Disponível em: $<$ <ttp://www.cpints.com/PDF/Bolonha\%20C.Sociais\%20\%20\%26\%20Servi\%25E70\%20Social.pdf>. Acesso em: 17 fev. 2017.

DECLARAÇÃO de Bolonha. 1999. Disponível em: <http://www.ehea.info/Uploads/ Documents/1999 Bologna_Declaration_Portuguese.pdf>. Acesso em: 28 out. 2016.

LIMA, Licínio C.; AZEVEDO, Mário Luiz Neves de; CATANI, Afrânio Mendes. O Processo de Bolonha, a avaliação da Educação Superior e algumas considerações sobre a Universidade Nova. Avaliação, v. 13, n. 1, p. 7-36, mar. 2008.

MOROSINI, Marília Costa. Internacionalização na produção de conhecimento em IES brasileiras: Cooperação internacional tradicional e cooperação internacional horizontal. Educação em Revista, v. 27, n. 1, p. 93-112, abr. 2011.

PORTUGAL. Decreto-Lei no 74, de 24 de março de 2006. Diário da República, 1a Série-A, n. 60, p. 2242-2257, 24 mar. 2006. Disponível em: <https://www.fct.pt/apoios/bolsas/DL 74_2006.pdf >. Acesso em: 17 fev. 2017.

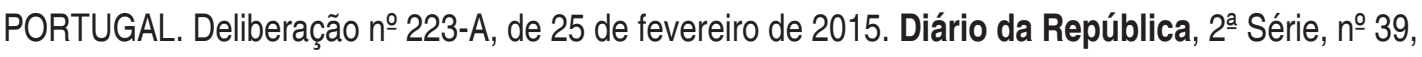
p. 4926 (2)-4926 (34), 25 de fevereiro de 2015. Disponível em: <https://sites.google.com/a/aebenfica. pt/aebenfica/documentos/historico/2014-2015/legislacao-essencial/deliberacao-no-223-a-2015-de-25de-fevereiro---pre-requisitos>. Acesso em: 17 fev. 2017.

PORTUGAL. Despacho normativo n. 43/2008. Estatutos da Universidade de Coimbra. Diário da República, 2. ${ }^{a}$ série. n. 168, p. 38329-38340, 1․ Set. 2008. Disponível em: <http://www.uc.pt/ governo/Estatutos UC.pdf>. Acesso em: 17 fev. 2017.

TAFFAREL, Celi Nelza Zulke. Formação de professores de Educação Física: Diretrizes para a formação unificada. Kinesis, v. 30, n.1, p.95-133, jan.jun. 2012.

TAFFAREL, Celi Nelza Zulke; TEIXEIRA, D. R.; D'AGOS, A. Cultura corporal e território: uma contribuição ao debate sobre reconceptualização curricular. Motrivivência, v.17, n.25, p.17-35, dez. 2005.

UNIVERSIDADE DE COIMBRA. Faculdade de Ciências do Desporto e Educação Física. Guia de PréRequisitos Candidatura 2015-2016. Disponível em: <http://www.uc.pt/fcdef/ensino/documentacao academica/Regulamento PR 2015.pdf>. Acesso em: 28 out. 2016.

UNIVERSIDADE DE COIMBRA. Faculdade de Ciências do Desporto e Educação Física. Plano de estudos. Disponível em: <https://apps.uc.pt/courses/PT/programme/847/20162017?id branch=12161>. Acesso em: 11 mar. 2016.

UNIVERSIDADE DE COIMBRA. Faculdade Ciências do Desporto e Educação Física. Processo de Adequação de Ciclo de Estudos. 2007. Disponível em: <http://www.uc.pt/fcdef/ensino/ documentacaoacademica/03LicCD1 - relatorio A-H 180 ECTS c.doc>. Acesso em: 28 out. 2016. 
UNIVERSIDADE ESTADUAL DE FEIRA DE SANTANA. Estatuto, 18 set. 2013. Disponível em: $<$ http://www.uefs.br/arquivos/File/ASPLAN/estatuto uefs.pdf>. Acesso em: 28 out. 2016.

UNIVERSIDADE ESTADUAL DE FEIRA DE SANTANA. Projeto Político Pedagógico do Curso de Licenciatura em Educação Física. Feira de Santana: Colegiado do Curso de Educação Física, 2011. p. 138.

UNIVERSIDADE ESTADUAL DE FEIRA DE SANTANA. Colegiado de Educação Física.

Componentes Curriculares e Ementas. Disponível em: <http://www1.uefs.br/portal/colegiados/ educacao-fisica/curso/componentes-curriculares-e-ementas>. Acesso em: 11 mar. 2016. 